Article

\title{
Five-Axis Milling of Large Spiral Bevel Gears: Toolpath Definition, Finishing, and Shape Errors
}

\author{
Álvaro Álvarez ${ }^{1}$, Amaia Calleja ${ }^{2, *(1)}$, Naiara Ortega ${ }^{2}$ and Luis Norberto López de Lacalle ${ }^{3}$ (10 \\ 1 Ibarmia, Polígono Industrial Etxesaga, s/n, 20720 Azkoitia, Spain; alvaro.alvarez@ibarmia.com \\ 2 Department of Mechanical Engineering, University of the Basque Country (UPV/EHU), \\ Alameda de Urquijo s/n, 48013 Bilbao, Spain; naiara.ortega@ehu.eus \\ 3 CFAA-University of the Basque Country (UPV/EHU), Parque Tecnológico de Zamudio 202, \\ 48170 Bilbao, Spain; norberto.lzlacalle@ehu.eus \\ * Correspondence: amaia.calleja@ehu.eus; Tel.: +34-946-017-347
}

Received: 1 April 2018; Accepted: 10 May 2018; Published: 15 May 2018

\begin{abstract}
In this paper, a five-axis machining process is analyzed for large spiral-bevel gears, an interesting process for one-of-kind manufacturing. The work is focused on large sized spiral bevel gears manufacturing using universal multitasking machines or five-axis milling centers. Different machining strategies, toolpath patterns, and parameters are tested for both gear roughing and finishing operations. Machining time, tools' wear, and gear surface are analyzed in order to determine which are the best strategies and parameters for large modulus gear manufacturing on universal machines. The case study results are discussed in the last section, showing the capacity of a universal five-axis milling for this niche. Special attention was paid to the possible affectations of the metal surfaces, since gear durability is very sensitive to thermo-mechanical damage, affected layers, and flank gear surface state.
\end{abstract}

Keywords: gears; multitasking machine; computer aided manufacturing (CAM)

\section{Introduction}

The large-sized spiral bevel gears represent one of the most important components of power transmission units in big machines, for mines and quarries, thermal power generation systems, marine propulsion elements, wind's kinetic energy applications, and so on [1,2]. Owing to the fact that there is presently an increase of energy requirements on the earth, the demand for large-sized spiral bevel gears has risen accordingly, and future technology predictions have singled out that it may continue to do so for some time.

Special gear cutting machines have traditionally manufactured these gears. In this regard, there are different methods for the gear-tooth surfaces generation. A few notable ones are the Gleason's gearing [3], the Klingelnberg's Palloid System [4], and the Klingelnberg's and Oerlikon's Cyclo Palliod System [5]. However, these methods are focused on medium and large batches production, for instance, gearboxes, cars transmissions, or outboard boats.

Gear manufacturing methods are defined for large batch production, and they are divided in those methods, usually in any kind of application making grooves, such as slotting with shaped mill tools, or general-purpose methods such as foundry or forge. In some cases, machining may start from a preform shape, for instance being obtained by forging, as it was studied in [6]. The methods that are more flexible are those that are based on the kinematics of gear meshing, in this case, the common ones are hobbing, shaping, skiving, and rack shaping. In bevel gears, the generation processes are very complicated, reaching the highest levels of complexity are the Gleason or Klingelnberg methods 
(face milling and face hobbing). The large spiral bevel gears are in a close area in which geometry depends on the manufacturing methods.

On the other hand, the emerging multitasking machines [7], along with numeric control and CAD/CAM software improvement, provide the appropriate media to manufacture the complex geometry gears with general purpose machines $[8,9]$. Nevertheless, they are applied to large modulus gears (modulus from 4 to $12 \mathrm{~mm}$ ), whereas the machine tools that are based on the generation methods are more suitable for the small modulus gears.

Free-form milling of gears has recently become more and more important as a flexible machining process for large modulus gears [10]. Flexible machining means that the gear geometry, process parameters, tools, and machines are not limited and fixed. The process does not depend on special tool geometries [11] for each gear type, since standard tools and universal machines can be used. The application area of gear types and sizes is theoretically not restricted. According to this, all of the conventional gear types and tooth geometries can be manufactured; the technology is flexible concerning new gear types designed with 3D modelling CAD packages. Furthermore, the tooth profile can be arbitrary and easily modified (tip relief, root relief, profile crowning, etc.). The methodology and strategies that are presented in this work are not limited to spiral bevel gears machining. In fact, they can also be applied to spur gears, helical gears, bevel gears, hypoid gears, and herringbone gears, amongst others. Gupta et al. [12] studied the gear manufacturing of complex bevel spiral and spiroid teeth. The digital closed-loop manufacturing technique, as a significant component of the spiral bevel gear manufacturing system, has provided a significant guarantee for improving the quantity and efficiency of spiral bevel gear tooth surfaces [13]. Residual stresses are key in gear finishing, in which there is a direct relation between the final residual stresses and life, as defined in Rego et al. [14]. Gear manufacturing also implies a whole branch of machining production, and, therefore, sustainability issues are important $[15,16]$.

This makes the proposed solution relevant for the manufacturing of gears on universal cutting machines in several applications, such as: (a) prototype manufacturing (preproduction development, motorsport applications, and rapid prototype parts), (b) single part production (cement mills, marine gear units, Jack up gear units for oil rings, and Jack up Vessels), (c) spare parts repair (marine, industrial, and large gear units), and (d) fundamental research parts manufacturing (variation of tool root geometry, running behavior on different gear surfaces).

In short, the gear manufacturing by free-form milling with standard milling tools on universal machine tools, is the combination of the conventional gear manufacturing technology on special machines, and the integrated NC (Numeric Control) machining of complex geometries on universal cutting machines. The work by Klocke et al. [17] was some of the first that defined the limits in quality of the general machining gear manufacturing approach. It is a common application in the last industrial exhibitions (EMO (Exposition Mondiale De La Machine-Outil (Machine Tool World Exposition), JIMTOF (Japan International Machine Tool Fair), or IMTS (International Manufacturing Technology Show)). Although the technology for process design and manufacture is still available [18-22], there is still a knowledge gap and industry interest concerning the potential of free-form milling of gears, with regard to feasible gear quality. Therefore, in this work, the free-form gear milling process capability is analyzed.

In the first section of this paper, the gear kinematic parameters are calculated in order to obtain the gear 3D geometry. Afterwards, gear teeth are machined using several machining strategies and parameters. Finally, the best machining strategies and parameters concerning roughness, shape errors, and machining productivity for gear free-form milling are analyzed.

The study provides large size gears, which are produced in the five-axis milling process description, this being a key aspect for the special, one-of-a-kind gears manufacturing. Moreover, the machining strategies panoply, expected times, tool wear, and surface quality values are analyzed, in order to maintain the gear quality under threshold values. The provided contributions include a case study description for the industrial application. 
The main contribution of the paper is to propose a method that is suitable for the production of one-of-kind large complex gears in machines that are not devoted to this task. Since EMO Hannover 2011, spiral gears manufacturing was only possible using dedicated machines, based on kinematic principles. The method that is proposed here is based on general machining. The pieces of universal multitasking or five-axis machines are three times lower than the dedicated machined, they can be used for multipurpose application, and there are several suppliers. The limit, until recent times, was repeatability and precision, but today $\mathrm{CNC}$ (Computer Numeric Control) machines can repeat a groove several times inside a repeatability of 3-4 micrometers.

\section{Integrated Rough-Finishing Approach}

The gear manufacturing process consists of several steps, the first being the gear geometry. Next, each step is described in detail.

\subsection{Design: CAD Step}

There are several options for gear design [23]. In fact, most of the commercial software have a modulus that is specifically dedicated to gear definition, namely: Solid Edge GearTrax module, SOLIDWORKS GearTrax module, Inventor Geartrax module, NX, Catia, or the application modules, such as 3D spiral bevel gear software, and so on. Some of them only included the design module, whereas the others also included the design and the manufacturing of the modules. In this work, in order to design the gear geometry, the 3D spiral bevel gear software (design module) was selected. The main reason for this software selection was the reduced license cost. The software generated gear geometry, and was able to choose between the Gleason and Klingelnberg manufacturing methods for the spiral gears.

The software mathematically modeled the gear mechanical systems (Gleason spiral bevel and Kligelnberg cyclo palloid). The software's main advantage was related to the good torque capacity results and reduced transmission error. Ideal gears transmitted higher torque and ran smoother at the nominal position and with the misaligned shafts. The 3D spiral bevel gear software accurately simulated the gear cutting methods with high resolution in 3D [24].

The spiral bevel gear geometry (Figure 1) was selected for the work. The objective was to select a complex and large geometry, in order to test the process's capability. A commonly used gear material, F1550 (18CrMo4), cemented the steel that could reach up to 47HRC. The 18CrMo4 was characterized by a core tensile strength after a case hardening and quenching of between 800-1250 MPa. The most common applications were bolts, pinions, cams, gears, speed gearboxes, plunger shafts, and rims. The chemical composition of this material appears in Table 1.

Table 1. Chemical composition of 18CrMo4 steel.

\begin{tabular}{ccccccccc}
\hline Standard & Grade & C & Mn & P & S & Si & Cr & Mo \\
\hline EN 10084 & 18CrMo4/1.7243 & $0.15-0.21$ & $0.60-0.90$ & 0.025 & 0.035 & $0.9-1.2$ & $0.9-1.2$ & $0.15-0.25$ \\
\hline
\end{tabular}

The geometry is manufactured according to the Gleason [3] method and the spiral bevel gearing parameters can be seen in Figure 1. 


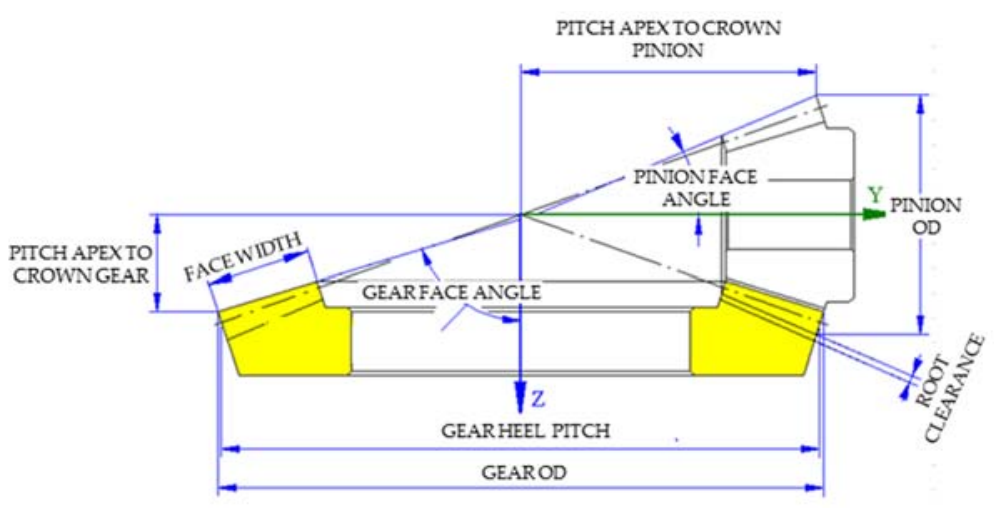

Figure 1. Spiral Bevel gear parameters.

The geometry parameters were introduced into the design software in three different steps (Table 2). Firstly, the preliminary data, such as the gear pitch diameter (or modulus), gear ratio, and right or left direction, were specified. Then, the gear and pinion data was defined according to the number of teeth in both cases, shaft, pressure and spiral angle values, gear face-width, gear transversal tooth-thickness on the heel, angular backlash on the gear, gear coefficient of addendum, coefficient of the tooth height, face cutter generating diameter, profile crowning, lead crowning, and coefficient of root radial clearance.

Table 2. Gear input and output data 3D spiral bevel gear software.

\begin{tabular}{lc}
\hline Step 1: Input Preliminary Data & \\
Gear heel pitch diameter (mm) & 200 \\
Ratio (pinion rmp/gear rpm) & 2 \\
Hand of spiral (left or rigth) & LEFT \\
Step 2: Finalize Data. Run 'Gear' 'Pinion' & \\
Shaft angle & 90 \\
Number of teeth on gear & 34 \\
Number of teeth on pinion & 17 \\
Gear face width (mm) & 34 \\
Preassure angle (deg) & 20 \\
Spiral angle (deg) & 35 \\
Gear transversal tooth thickness on heel (mm) & 9 \\
Angular blacklash gear (deg) & 0.15 \\
Gear coef. of addendum & 1 \\
Coef. of tooth height & 2.25 \\
Face cutter generating diameter (mm) & 140 \\
Profile crowning (mm) & 0.005 \\
Lead crowning (mm) & 0.002 \\
Coef. root radial clearance & 0.25 \\
Output & \\
Gear face angle (deg) & 66.37533996 \\
Pinion face angle (deg) & 29.64876178 \\
Pinion od (mm) & 108.947 \\
Gear od (mm) & 204.435 \\
Pitch apex to crown on pinion (mm) & 97.763 \\
Pitch apex to crown on gear (mm) & 45.564 \\
Root clearance (mm) & 0.783 \\
Pinion heel pitch diameter (mm) & 100 \\
Pinion transversal tooth thickness on heel (mm) & 9.218 \\
Face cutter radial distance (mm) & 79.214 \\
\hline
\end{tabular}

Finally, the software provided an indispensable output data for 2D (2 Dimension) design, namely: gear and pinion face angles, exterior diameter values, pitch apex to croon on pinion/gear, root 
clearance value, pinion heel pitch diameter, pinion transversal tooth thickness on heel, and face cutter radial distance.

The function provided both pinion and gear 2D geometries (Figure 2), according to the spiral bevel gears' manufacturing process (by pairs). The design that was provided was a 2D design that needed to be revolted through the axial axis, in order to obtain a 3D feature. Afterwards, the teeth surface was imported and a circular matrix was carried out, in order to design the complete gear (Figure 3).

The 3D spiral bevel gear software also analysed the tool contact position (Figure 4). The gear teeth lead and profile crowing diagrams were obtained. The contact area was the key for complex gears performance, as it has been deeply studied by Fuentes et al. [25], because, in theory, the gears contact would have been a line or curve, but real geometry caused a contact area.

For instance, in Figure 5, the contact was focused on the teeth toe-tip area and the kinematics of the Gleason method were reproduced. In gear meshing, slight changes in the profile shapes caused a very different tooth-tooth contact patterns. Therefore, it would be recommended that if there was to be any modification for future gear performance, the five-axis milling technology represented an appropriate applicable technology. Modifications could be easily applied to machining the correct toolpath programming. In the generation gear manufacturing (the usual methods for medium and large batches), the tooth contact needed to change with the complicated changes in cutters, or make a complex modification in the machine parameters. On the other hand, in the five-axis approach, the modifications could be easily machined. Moreover, today a Gleason spiral bevel could be produced, tomorrow it could be the Palloid, or the Klingelnberg, or any other type of spiral bevel. The five-axis would allow for any modifications. The five-axis milling offered a versatility and open geometry design.
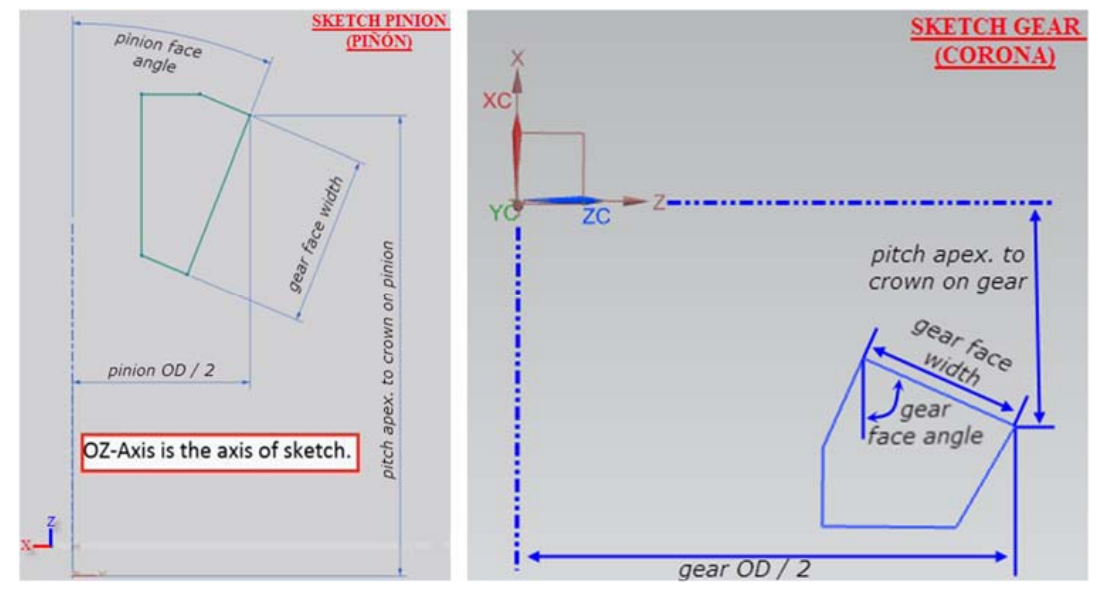

Figure 2. 2D geometry provided by 3D spiral bevel gear software.

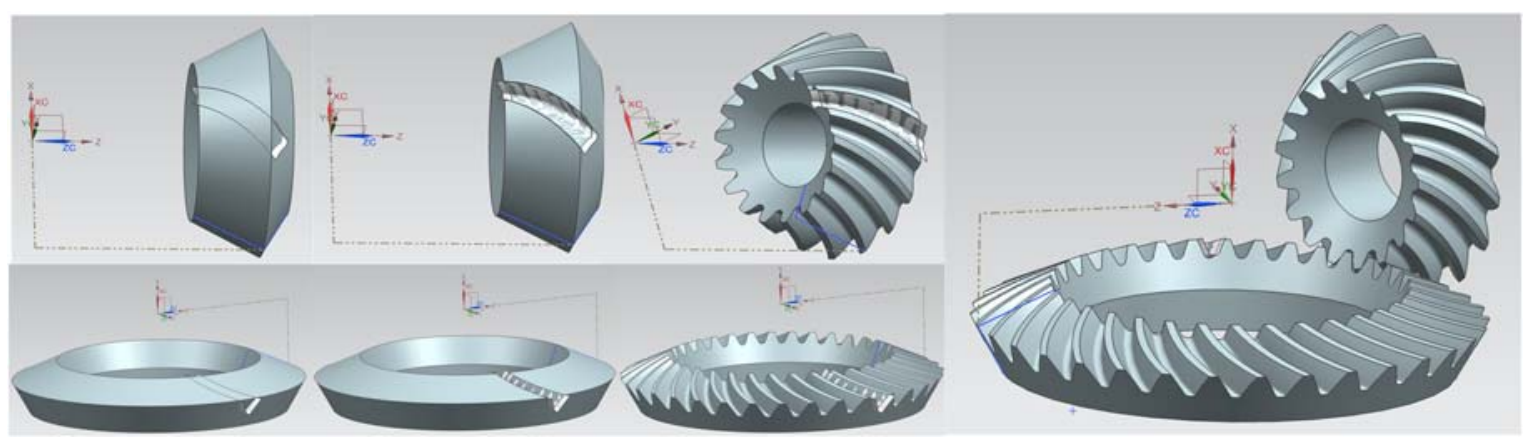

Figure 3. Gear design from 2D geometry to 3D geometry. 


\section{Tooth Contact Analyses}
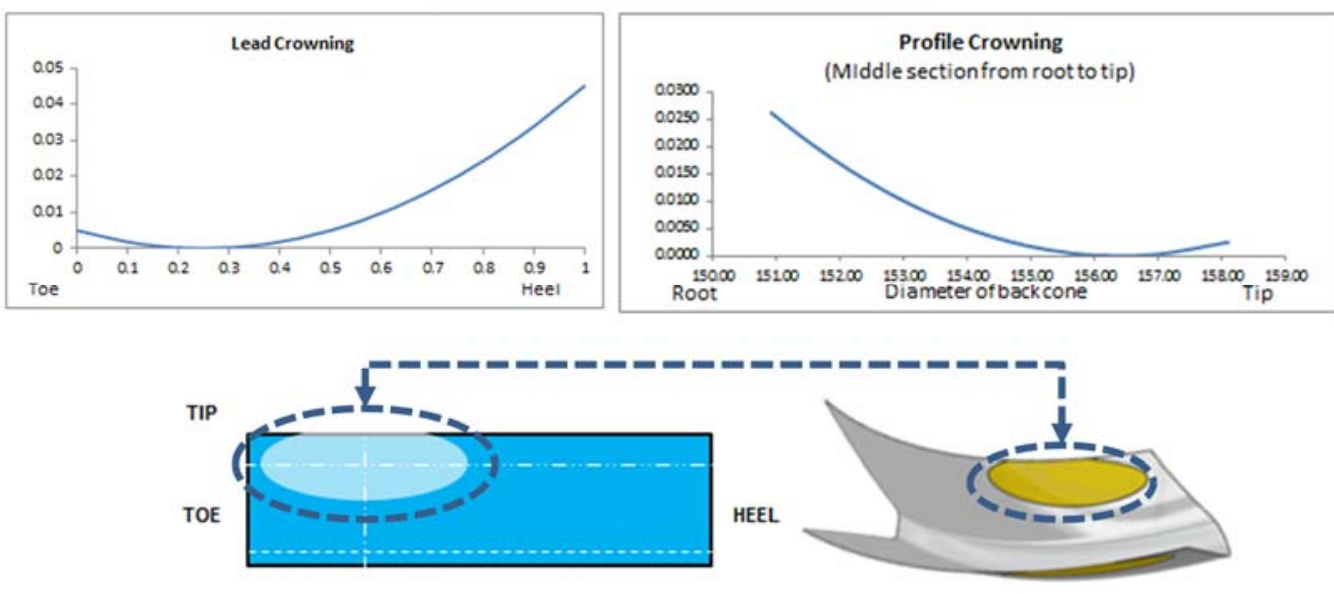

ROOT

Figure 4. Gear tool contact analysis example, obtained from software.

\subsection{Manufacturing Trajectories Design: CAM Step}

Once the gear geometry was obtained and analyzed, the different manufacturing trajectories were designed with the NX 10 (Siemens) Manufacturing module. Several strategies were tested for roughing and finishing the operations. For the roughing strategies, cavity mill and variable contour patterns were followed. In both cases, the number of interpolated axes and followed toolpath selection (stream line, followed periphery, surface area, and trochoidal) method was tested. The main objective for the roughing strategies selection was to reduce the machining time as much as possible and to obtain a near to net shape geometry. On the other hand, for the finishing strategies, zig or zig/zag patterns were selected, and the surface area with a relative vector orientation was chosen. In all cases, various scallop values were machined in order to determine which was the best machining strategy, in terms of the machining time and component quality.

\subsection{Experimental Set Up: Multiprocess Machine}

The gear was manufactured in the multiprocess machine ZVH38/L1600 (Figure 5), which was developed by Ibarmia. The machine was appropriated for turning and milling operations and integrated three linear axes $(X, Y$, and $Z)$ in the moving column and two rotary axes, one of which was integrated in the tilting head (B) and the other one in a rotary table (C). The efficiency that was associated to the multiprocess centers improved the quality of the final piece, as fewer machines and thus fewer piece set-ups were required; it reduced the cost of the initial investment and the floor space that was required, the transit of pieces between machines was eliminated, and the production management was simplified. A precision auto-centering fixture was used for the gear manufacturing, namely, the Fresmak self-centering clamp 'Arnold SC'. It was a mechanical fixture system for great precision in self-centering. There was an accuracy of $0.01 \mathrm{~mm}$ in the clamping repeatability and $0.02 \mathrm{~mm}$ in the centering. It was especially designed to work on machining centers with small tables, as well as within five controlled axes machining centers. It presented a compact design with exterior guides that avoided deformation, as the clamping force was distributed throughout the width. The clamping force ranged from 10 to $35 \mathrm{kN}$. 

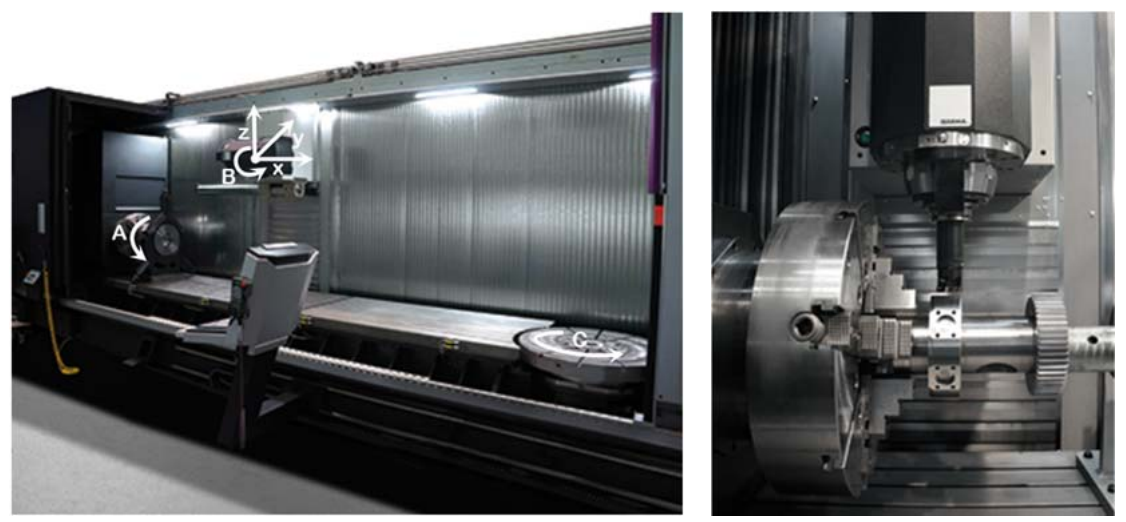

Figure 5. Ibarmia multiprocess machine ZVH38/L1600 (left), Ibarmia ZVH38/L1600 A axis and head (right).

\subsection{Integrated Roughing-Semifinishing-Finishing Approach}

The gear was machined according to three stages, namely the roughing-semifinishing-finishing approach. The machining strategies were programmed with NX SIMENS CAM software. The roughing strategies for optimal finishing [26] were designed to take into account minimum chip thickness and constant cutting forces' requirements. The minimum chip thickness were associated with the lower and constant cutting forces rather than the larger chip thickness values. Therefore, the unexpected cutting forces' high and variable values were avoided, and as a consequence, possible machining errors, such as material overcut or undercut (dimensional errors), were not present $[27,28]$. For the roughing process (Table 3), five different machining strategies were tested. Five gear teeth were machined for each roughing strategy (see Table 4).

Table 3. Roughing machining parameters.

\begin{tabular}{cccc}
\hline Feed $(\mathbf{m m} / \mathbf{m i n})$ & Speed $(\mathbf{r p m})$ & Depth of Cut Per Pass $(\mathbf{m m})$ & Cutting Fluid \\
\hline 230 & 9550 & 0.5 & Conventional oil and water emulsion coolant \\
\hline
\end{tabular}

Table 4. Roughing strategies information.

\begin{tabular}{cccc}
\hline & Roughing Strategy & Tooth Number & Machining Time \\
\hline R-I & $\begin{array}{c}\text { Cavity mill (3+ 1-axis) } \\
\text { Follow periphery }\end{array}$ & $1,2,3,4,5$ & $5^{\prime} 11^{\prime \prime}$ \\
\hline R-II & $\begin{array}{c}\text { Variable contour (5-axis) } \\
\text { Stream line }\end{array}$ & $6,7,8,9,10$ & $4^{\prime} 15^{\prime \prime}$ \\
\hline R-III & $\begin{array}{c}\text { Variable contour (5-axis) } \\
\text { Stream line }\end{array}$ & $11,12,13,14,15$ & $3^{\prime} 54^{\prime \prime}$ \\
\hline R-IV & $\begin{array}{c}\text { Variable contour (5-axis) } \\
\text { Surface area + Stream line }\end{array}$ & $16,17,18,19,20$ & $2^{\prime}$ \\
\hline R-V & $\begin{array}{c}\text { Cavity mill (3 + 1-axis) } \\
\text { Throchoidal }\end{array}$ & $21,22,23,24,25$ & $11^{\prime} 42^{\prime \prime}$ \\
\hline
\end{tabular}

In the R-II to R-IV, five-axis milling was used, while in R-I and R-V, a cavity mill strategy was programmed. The main difference between the R-I and R-V was that the machining pattern that was selected for R-I followed a geometry periphery, whereas for R-V the selected, the machining pattern was trochoidal. The R-II, R-III, and R-IV strategies were based on variable contour strategies. Standard three-flute tools were used for the roughing strategies (Ø $14 \mathrm{~mm}$ ).

As shown in Figure 6, the R-I strategy corresponded to a roughing cavity mill strategy. Follow periphery (inward pattern direction) was the cut pattern that was used, the radial and axial 
depths (50\% tool diameter) were specified, and the tool went up to a clearance plane between the different milling regions. Three linear axes and one indexed rotary axis were required for this strategy.
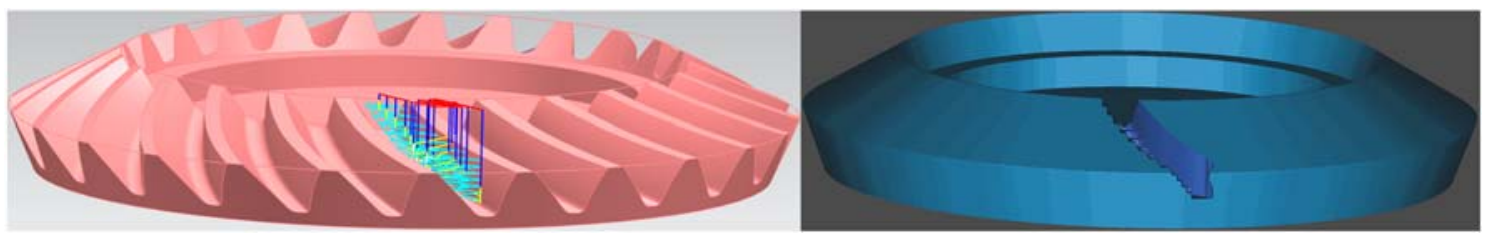

Figure 6. R-I roughing strategy.

The second roughing strategy, R-II (Figure 7), corresponded to a continuousfive-axis strategy. In this case, a variable contour strategy was selected. The selected cut pattern was zig/zag and the tool axis lead angle was set to $180^{\circ}$, relative to the $z$ axis. Six different levels and strategies were programmed, in order to machine the complete cavity between two gear teeth. Initially, the cavity width required more than one pass while, at the bottom, only one pass was required.
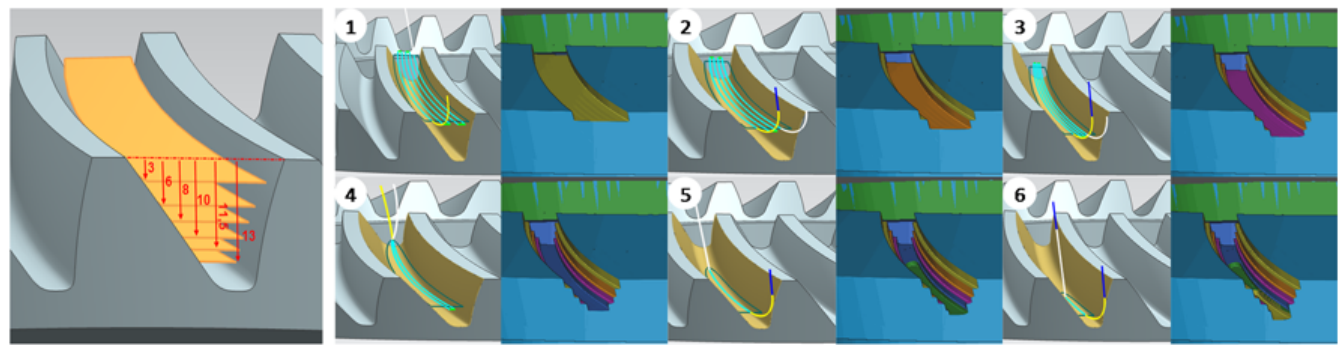

Figure 7. R-II roughing strategy.

The R-III (Figure 8) roughing strategy was similar to the R-II roughing strategy. The variable contour strategies and streamline selection were programmed in both cases. In this case, the cut pattern that was programmed is zig/zag and tool axis lead angle was set to $180^{\circ}$, relative to the $z$ axis. The main difference between them was that the axial depths values varied.
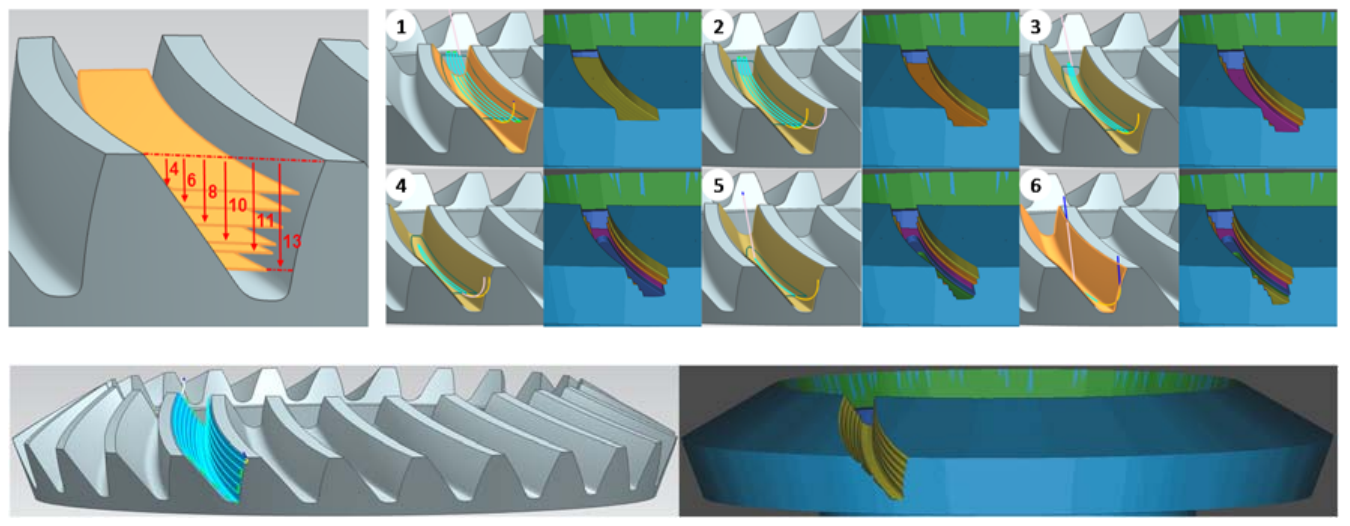

Figure 8. R-III roughing strategy. Strategy axial depth progress is shown in 1-6.

For R-IV, larger axial depths values were programmed at the beginning, and small axial depths values were programmed for the last passes. In addition, a semi-finishing strategy was programmed in order to obtain a near-to-final geometry, so as to open up the finishing strategy.

The R-IV (Figure 9) followed the R-II and R-III strategies but, in this case, eight passes were programmed using smaller axial depth values. 


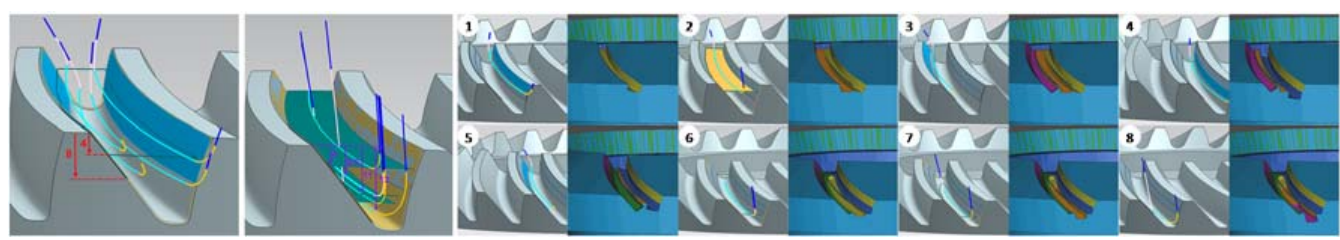

Figure 9. R-IV roughing strategy.

Finally, for R-V (Figure 10), the cavity mill strategy was programmed once again. In this case, the efficient trochoidal milling pattern was selected. The outward pattern direction was selected for the trochoidal milling and the radial distance between trochoidal movements was limited to $45 \%$ tool diameter.

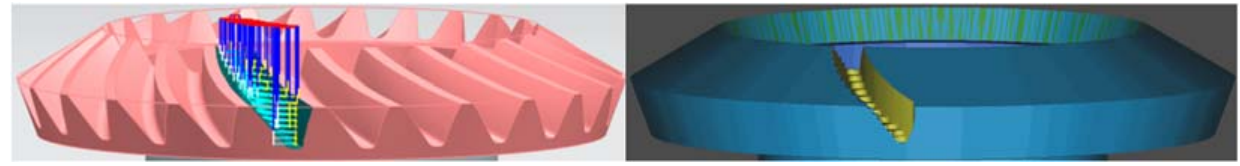

Figure 10. R-V roughing strategy.

After the machining time comparison (Table 5), surprising results could be observed. According to the CAM software time prediction, the efficient trochoidal strategies were not the fastest machining strategies. In this case, although at simple sight the R-IV seemed to be the largest machining because of the number of steps that were used, it corresponded to the fastest machining strategies. On the other hand, the tool wear was not significant in any of the cases and further longer testing should have been performed so that this effect would have been relevant.

In Table 3, the finishing operations information is shown. For the finishing operations and the roughing operations, five different strategies were tested for every five teeth group. In these cases (Figure 11), the surface area operations were programmed to zig and zig-zag selected cut patterns. The tool was oriented according to the relative to vector option.
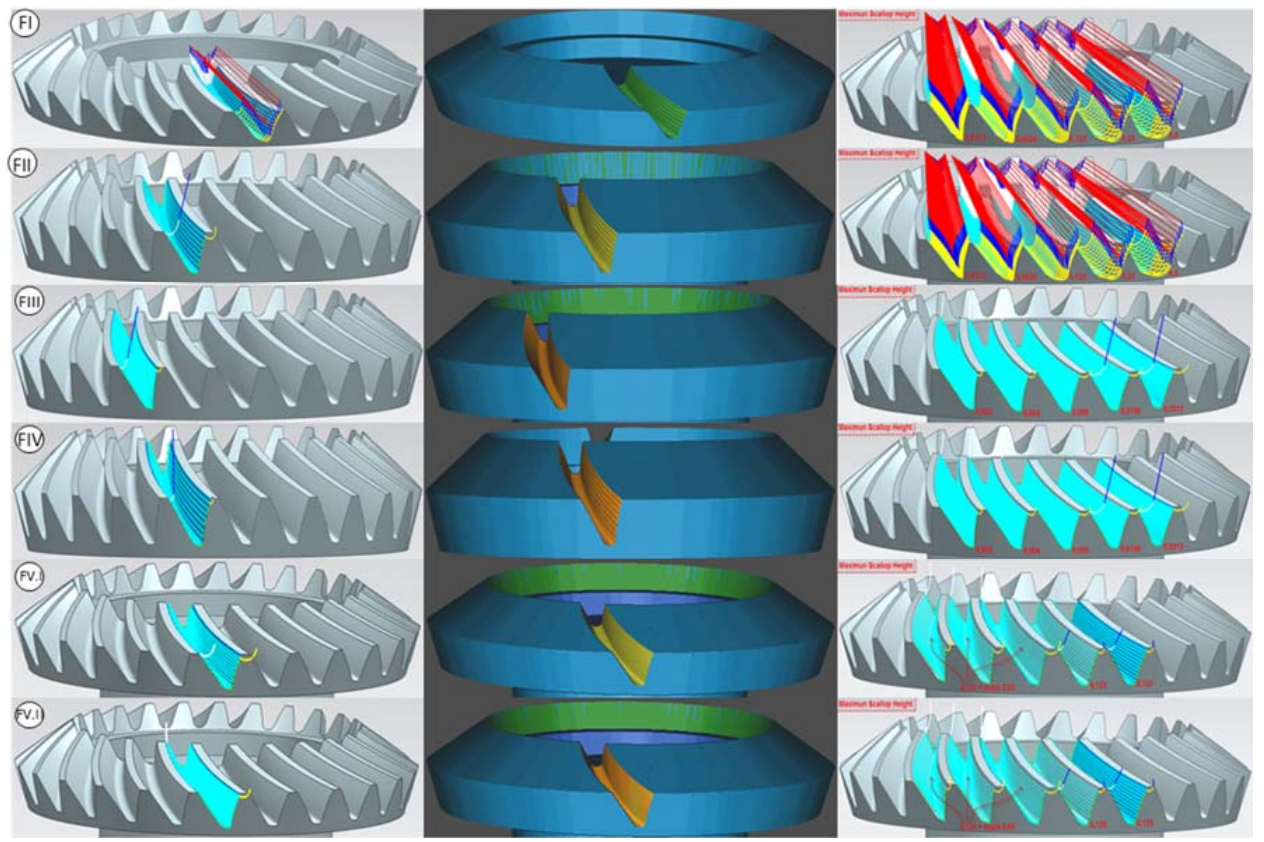

Figure 11. Finishing operations. Machined finishing operations explained in Table 5 are shown in F-I-F-V.2. 
Table 5. Finishing strategies information.

\begin{tabular}{cccc}
\hline & Finishing Strategy & Tooth Number (Groove) & Machining Time \\
\hline \multirow{4}{*}{ F-I } & Surface area + relative vector & 1 & $8^{\prime} 58^{\prime \prime}$ \\
& Cut pattern & 2 & $4^{\prime} 31^{\prime \prime}$ \\
& (Scallop 0.004-0.004-0.002-0.002-0.002) & 3 & $12^{\prime} 59^{\prime \prime}$ \\
& & 4 & $6^{\prime} 24^{\prime \prime}$ \\
& Surface area + relative vector & 5 & $6^{\prime} 24^{\prime \prime}$ \\
\hline F-II & Cut pattern & 6 & $8^{\prime} 58^{\prime \prime}$ \\
& zig(6,8)-zig/zag(7,9,10) & 7 & $4^{\prime} 31^{\prime \prime}$ \\
& (Scallop 0.004-0.004-0.002-0.002-0.002) & 8 & $12^{\prime} 59^{\prime \prime}$ \\
& & 9 & $6^{\prime} 24^{\prime \prime}$ \\
F-III & Surface area + relative vector & 10 & $6^{\prime} 24^{\prime \prime}$ \\
& Cut pattern & 11 & $11^{\prime} 58^{\prime \prime}$ \\
& zig(11,13)-zig/zag(12,14,15) & 12 & $6^{\prime} 53^{\prime \prime}$ \\
& (Scallop 0.004-0.004-0.002-0.002-0.002) & 13 & $16^{\prime} 40^{\prime \prime}$ \\
& & $9^{\prime} 45^{\prime \prime}$ \\
F-IV & Surface area + relative vector & 14 & $9^{\prime} 45^{\prime \prime}$ \\
\hline F-V.1 & Cut pattern & 15 & $8^{\prime} 58^{\prime \prime}$ \\
& zig(16,18)-zig/zag(17,19,20) & 16 & $4^{\prime} 31^{\prime \prime}$ \\
& (Scallop 0.004-0.004-0.002-0.002-0.002) & 17 & $12^{\prime} 59^{\prime \prime}$ \\
& Surface area + relative vector & 18 & $6^{\prime} 24^{\prime \prime}$ \\
$6^{\prime} 24^{\prime \prime}$
\end{tabular}

The difference between the finishing operations was the scallop value (Figure 12). Values between 0.002-0.004 $\mathrm{mm}$ were programmed. In fact, this parameter strongly influenced the surface finishing results, as it is shown later. As it can be seen in Figure 12, the programmed scallop height value and stepover distance determined the surface roughness results. For the finishing operations, ball-tapered-end mills were used for all of the finishing operations, except for F-V.2. In this last case, an air turbine with a CBN (Cubic Boron Nitride) grinding stone tip is used. The machining time comparison can be seen in Table 5 . The finishing strategies and results have been analyzed in the results section.

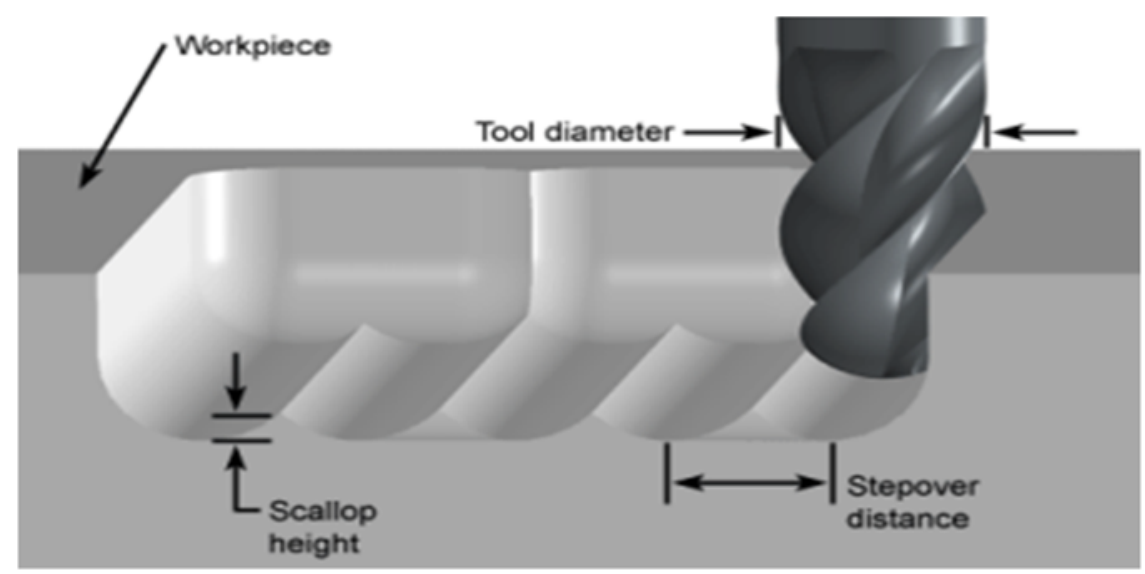

Figure 12. Scallop parameter representation. 


\subsection{Machining}

Programmed strategies were machined and, in Figure 13, the gear result after the roughing strategies (R-I for teeth 1 to 5, R-II for teeth 6-10, R-III for teeth 11-15, R-IV for teeth 16-20, and R-V for teeth 21-25) and the gear result after the finishing strategies (F-I for teeth 1 to 5, F-II for teeth 6-10, F-III for teeth 11-15, F-IV for teeth 16-20, and F-V for teeth 21-25) can be observed.
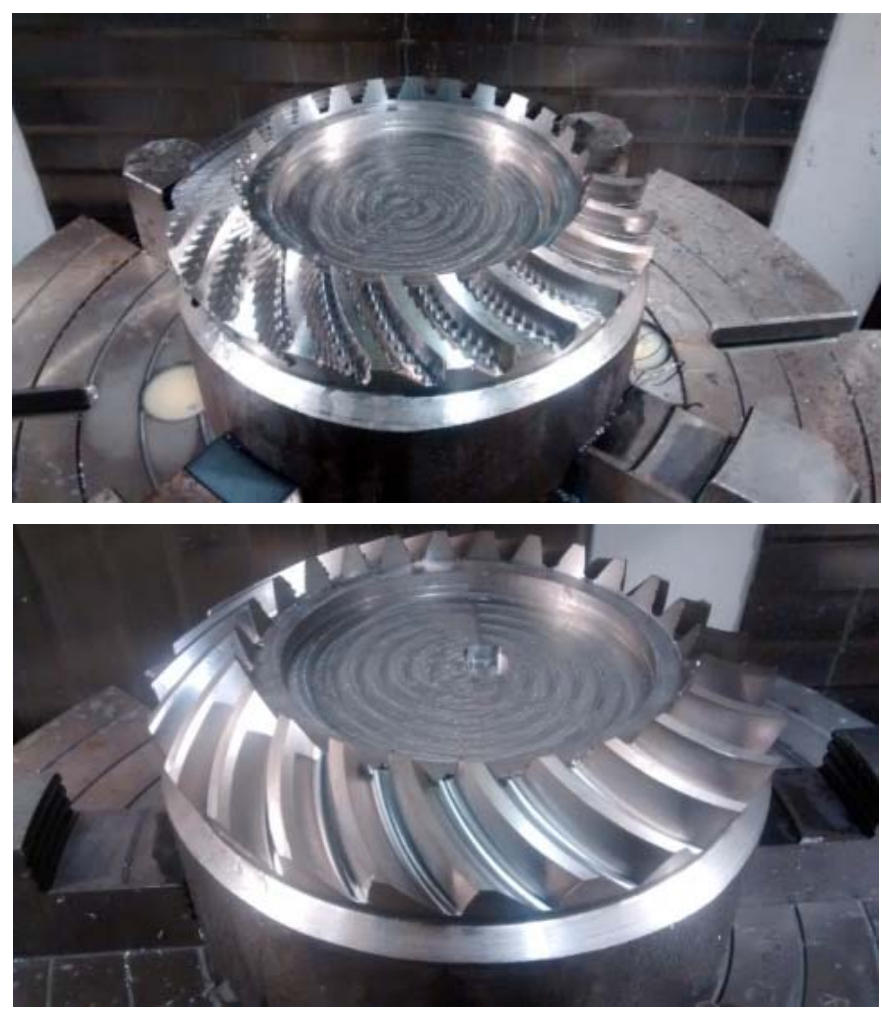

Figure 13. Gear after rough (top) and finish machining (bottom).

\section{Results}

\subsection{Roughness Analysis}

The surface analysis of the gears was carried out with optic equipment. Confocal tridimensional Leica DMC 3D (Leica, Wetzlar, Germany) and contact profilometer Taylor Hobson Form Taylorsurf (Taylor-Hobson, Leicester, UK) were used for the 2D and 3D roughness measurement, according to ISO 4287 (Figure 14). The roughness values are shown in Table 6.

In Figure 15, a surface 3D scanning that corresponds to the tooth 17 is shown, where the periodic tool marks can be clearly observed. The tooth 17 roughing strategy corresponds to a 'variable contour five-axis' operation where 'surface area with stream line' is used for geometry selection. Moreover, the surface area operation and relative vector orientation with a zig/zag pattern and $0.004 \mathrm{~mm}$ scallop value were used for the finishing strategy. 


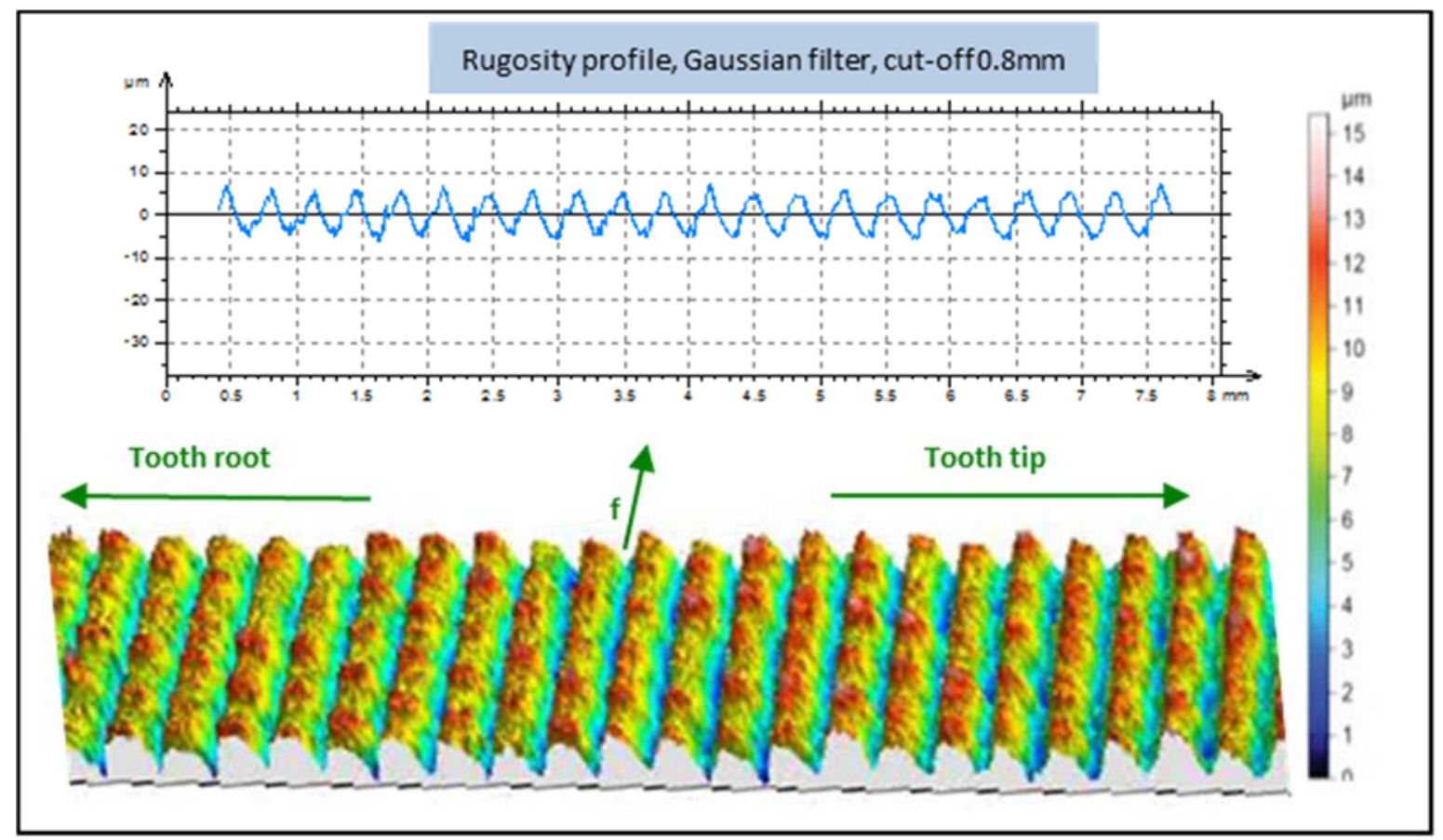

Figure 14. Surface analysis results.

Table 6. Roughness values ( $\mu \mathrm{m})$.

\begin{tabular}{|c|c|c|c|c|c|c|c|c|c|c|c|c|c|c|c|c|c|c|c|c|c|c|c|c|c|}
\hline $\begin{array}{c}\text { Finishing } \\
\text { Strategy Group }\end{array}$ & & & 1 & & & & & 2 & & & & & 3 & & & & & 4 & & & & & 5 & & \\
\hline Tooth Number & 1 & 2 & 3 & 4 & 5 & 6 & 7 & 8 & 9 & 10 & 11 & 12 & 13 & 14 & 15 & 16 & 17 & 18 & 19 & 20 & 21 & 22 & 23 & 24 & 25 \\
\hline $\mathrm{Ra}$ & 1.0 & 2.9 & 1.4 & 1.8 & 2.2 & 1.3 & 2.9 & 1.1 & 1.8 & 1.9 & 0.7 & 2.5 & 0.5 & 1.5 & 1.6 & 0.8 & 2.2 & 0.6 & 1.1 & 1.1 & 2.0 & 2.6 & 2.2 & 2.8 & 0.8 \\
\hline $\mathrm{Rz}$ & 4.9 & 10.9 & 11.7 & 8.2 & 8.8 & 7.0 & 11.9 & 8.1 & 9.5 & 9.6 & 3.7 & 10.3 & 2.9 & 7.2 & 7.2 & 4.3 & 9.5 & 3.3 & 5.3 & 5.3 & 11.8 & 14.8 & 11.7 & 14.4 & 4.5 \\
\hline
\end{tabular}




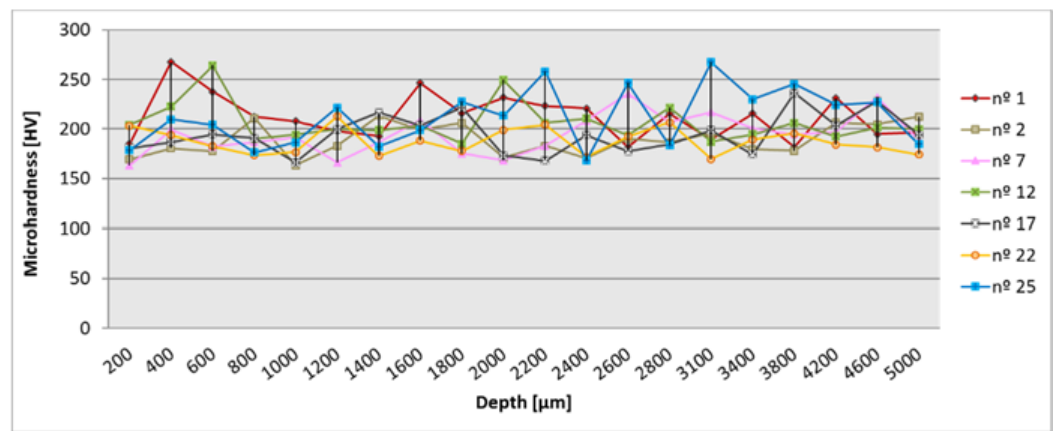

Figure 15. Microhardness measured in tooth no (number) 1, 2, 7, 12, 17, 22, and 25.

\subsection{Surface Integrity}

In this section, the effect of the machining conditions on the material structure will be analyzed. The objective was to assure the health of the material for the subsequent heat treatment. To this end, specimens were extracted from the gear and were subsequently polished. The microhardnesses were obtained in the flanks (Figure 15) and, later, they were attacked by etchant ( $2 \%$ Nital) to reveal the microstructure. The following graph shows the microhardness values that were obtained in the flanks, relative to the different teeth.

This graph indicates that there was no hardness change in the gear under any of the machining conditions that were imposed. With the aim of assuring this point, in Figure 16, the micrographs that were extracted after the attack are shown. Micrographs (a), (b), (c), and (d) belonged to the milled gear flanks, whereas (e) micrograph corresponded to a ground flank. As it is known, during cutting, high temperatures were reached in the interface between the rake face of the tool and the chip. In grinding, these temperatures were usually much higher as a result of the large deformation of the workpiece material during the cutting process. Up to $90 \%$ of the consumed power was converted into heat $[29,30]$ during grinding, which, in most of the severe cases, caused a phase change in the workpiece subsurface [31].

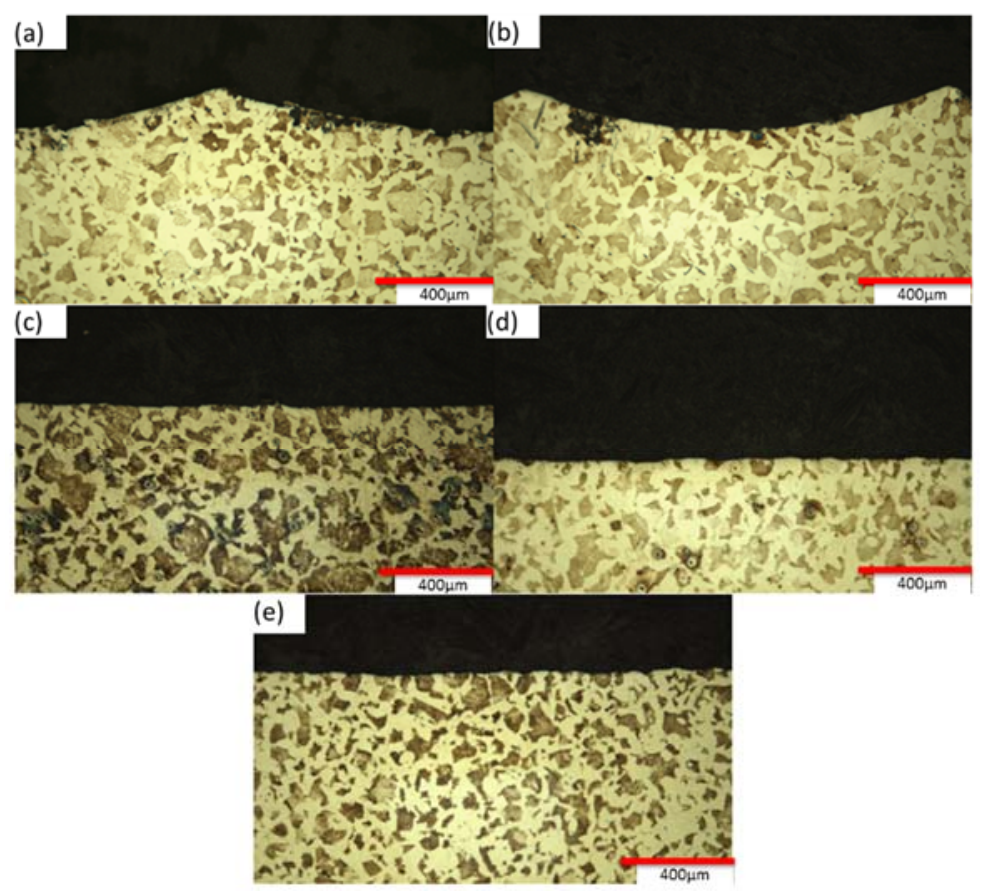

Figure 16. Micrographs taken at 100× from teeth: (a) no 3, (b) no 6, (c) no 18, (d) no 23, and (e) no 25. 
In this work, the provided strategies were conservative from this point of view, since the figures corroborated that the microstructure had not been modified in any of the cases. In fact, the images show the typical microstructure of the as-received sample, which showed a pearlite (dark) in the matrix of the ferrite (white), from the very beginning of the surface to the material core. In this instance, no other phase could be observed, and no material damage was encountered during milling and during grinding with the CBN wheels under the established conditions.

\subsection{Form Deviation}

The tooth flank form deviation was measured (Figure 17) for tooth number 17. The profile form had a quality of class 1 , which meant that the measured error was under $2 \mu \mathrm{m}$. In this case, the trajectory was oriented in the gear width direction, so that the feed marks would have been visible as a tooth flank form deviation. The form deviation measurement was carried out with an optical light microscope, Leica DCM 3D. The equipment combined confocal and interferometry technology for high speed and high-resolution measurements, down to $0.1 \mathrm{~nm}$.

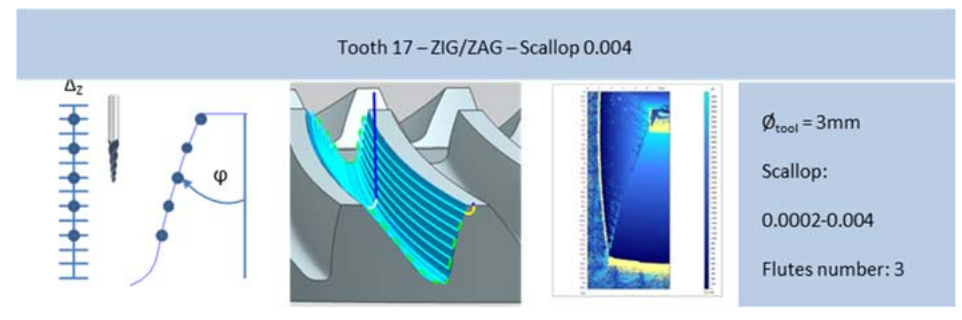

Figure 17. Form deviation results.

\subsection{Pitch Deviation}

Gears form milling was a discontinuous indexing process, every gap was machined separately. Therefore, a pitch deviation analysis (Figure 18) was required. With the aim of measuring the final dimension and pitch deviation, and gear component was scanned with an ATOS GOM (GOM, Braunschweig, Germany). This equipment was based on the triangulation effect, using two cameras with a resolution of $17 \mu \mathrm{m}$ and an accuracy of $35 \mu \mathrm{m}$. In Figure 18, the comparison between the scanned surface and the defined CAD model is shown. For the pitch deviation measurement of the gear teeth, the surface points were measured for each teeth surface and angle definition. After the points measuring process, the cloud of points was compared to the CAD model in order to determine the error. In this case, a rectangular slot was machined in the workpiece surface in order to determine each teeth position in relation to a reference.
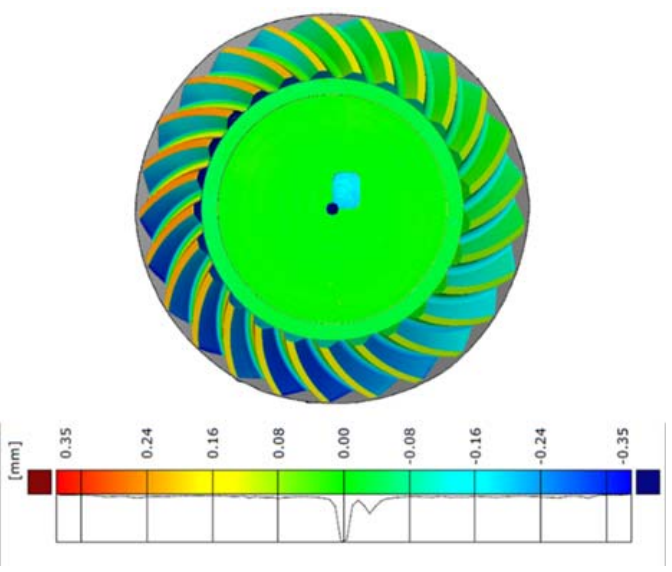

Figure 18. Pitch deviation results. 
The results that were registered between the manufactured gear surfaces and CAD model met the acceptable tolerance requirements for large spiral gears manufacturing $( \pm 0.1 \mathrm{~mm})$, which is what made five-axis milling in multitasking machines appropriate for gears manufacturing.

\section{Discussion}

After the large size gears that were produced in the five-axis milling universal machine, the main objective of the study was reached, which showed the capacity of the universal five-axis milling for this niche.

Surprising results could be observed for the roughing strategies. The efficient trochoidal strategies were not the fastest machining strategies. The distance between the teeth determined the tool diameter and the distance between the trochoidal movements. In this example, many small movements were required for the roughing strategy, and, therefore, the machining time was increased. In this case, although at simple sight R-IV seemed to be the longest machining operation because of the number of steps that were used, it corresponded to the fastest machining strategies. Furthermore, the finishing strategies showed that the programmed scallop height value and stepover distance determined the surface roughness results. The roughness peaks and valleys corresponded to the tool step that, at the same time, depended on the programmed stepover.

After the roughness analysis, the surface integrity and form, and pitch deviation, it could be concluded that the universal five-axis milling machines were appropriate for large size gears production, since the surface quality and dimensional quality was guaranteed.

On the other hand, as stated at the beginning, the work was limited to short batch production and large geometries.

Future work with other geometries and materials would determine more industrial applications viability.

Finally, the proposed method, which was suitable for the production of one-of-kind large complex gears in general purpose machines, was the main contribution of the study in the gear cutting literature.

\section{Conclusions}

Gear free-form manufacturing on universal milling machines represents a real industry tendency. The main reasons for this are related to the manufacturing flexibility. Different gear geometries and sizes are manufactured with the same equipment. Several conclusions are pointed out.

Standard tools are used for these manufacturing processes. Universal tools that provide short times, tools from a wide range, and competitive prices are the main advantages. Moreover, the gear is manufactured according to one set up in one machine, which reduces the machining ties and transference times between the different machines.

Trochoidal, or deep grooving approaches, were discovered as useful for spiral gears, since the machining time for cavity volume is expected.

The machining strategy is fully defined in this paper. In this sense, the machining trajectories (path of tool movement during the cutting process), cutting tools, and cutting conditions are evaluated.

Finally, the process quality analysis is developed, taking into account the surface analysis, tooth flank form deviations, and pitch angle deviations.

Author Contributions: Á.Á. and A.C. designed and performed the experiments. Additionally, Á.Á. and A.C. analyzed the roughness and form, and pitch deviation. A.C. wrote the paper. N.O. analyzed the data related to surface integrity and dimension accuracy. Finally, L.N.L.d.L. contributed to the resources (machine, tools, material, etc.) and supervised all of the work carried out in this research.

Funding: This research received no external funding.

Acknowledgments: Thanks are addressed to the Department of Education, and to the Universities and Research of the Basque Government for their financial support, by means of the ZABALDUZ program. We thank also the UFI in Mechanical Engineering department of the UPV/EHU for its support to this project. 
Conflicts of Interest: The authors declare no conflict of interest. The founding sponsors had no role in the design of the study; in the collection, analyses, or interpretation of data; in the writing of the manuscript; and in the decision to publish the results.

\section{References}

1. Qin, Z.; Luo, Y.; Li, K.; Peng, H. Optimal design of a novel hybrid Electric powertrain for tracked vehicles. Energies 2017, 10, 2141. [CrossRef]

2. Xu, G.; Hua, D.; Dai, W.; Zhang, X. Design and performance analysis of a coal bed gas drainage machine based on incomplete non-circular gears. Energies 2017, 10, 1933. [CrossRef]

3. Stadtfeld, H.J. Gleason Bevel Gear Technology: The Science of Gear Engineering and Modern Manufacturing Methods for Angular Transmissions; Gleason Works: Rochester, NY, USA, 2014; ISBN 9780615964928.

4. Watson, H.J. Gear Milling. In Modern Gear Production; Elsevier: New York, NY, USA, 1970; Chapter 8; pp. 146-158. ISBN 9780080158358.

5. Lechner, G. Klingelnberg spiral bevel gears. J. Mech. 1968, 3, 217-218. [CrossRef]

6. Zhuang, W.; Hua, L.; Han, X.; Zheng, F. Design and hot forging manufacturing of non-circular spur bevel gear. Int. J. Mech. Sci. 2017, 133, 129-146. [CrossRef]

7. Calleja, A.; Gonzalez, H.; Polvorosa, R.; Ortega, N.; Lopez-de-Lacalle, L.N. Multitasking machines: evolution, resources, processes and scheduling. DYNA 2017, 92, 637-642. [CrossRef]

8. Suh, S.H.; Jih, W.S.; Hong, H.D.; Chung, D.H. Sculptured surface machining of spiral bevel gears with CNC milling. Int. J. Mach. Tool Manuf. 2001, 41, 833-850. [CrossRef]

9. Kawasaki, K.; Tsuji, I.; Abe, Y.; Gunbara, H. Manufacturing method of large-sized spiral bevel gears in cyclo-palloid system using multi-axis control and multi-tasking machine tool. In Proceedings of the International Conference on Gears, Garching, Germany, 4-6 October 2010; pp. 56-61.

10. Uzun, $\mathrm{M}$. The investigation on manufacturing time of a new type concave-convex gear by a CNC milling machine. Int. J. Adv. Manuf. Technol. 2015, 77, 1275-1280. [CrossRef]

11. González, H.; Calleja, A.; Pereira, O.; Ortega, N.; López de Lacalle, L.N.; Barton, M. Super abrasive machining of integral rotary components using grinding flank tools. Metals 2018, 8, 24. [CrossRef]

12. Gupta, K.; Jain, N.K.; Laubscher, R. Manufacturing of conical and noncircular gears. In Advanced Gear Manufacturing and Finishing; Academic Press: Cambridge, MA, USA, 2017; Chapter 3; pp. 53-66.

13. Li, J.-B.; Ma, H.J.; Deng, X.Z. An approach to realize the networked closed-loop manufacturing of spiral bevel gears. Int. J. Adv. Manuf. Technol. 2017, 89, 1469-1483. [CrossRef]

14. Rego, R.; Löpenhaus, C.; Gomes, J.; Klocke, F. Residual stress interaction on gear manufacturing. J. Mater. Process. Technol. 2018, 252, 249-258. [CrossRef]

15. Gupta, K.; Laubscher, R.F.; Davim, J.P.; Jain, N.K. Recent developments in sustainable manufacturing of Gears: A review. J. Clean. Prod. 2016, 112, 3320-3330. [CrossRef]

16. Lin, C.; Cheng, K.; Qin, D.; Guo, Q.; Zhou, P.; Qiu, H. An investigation on high-speed dry gear hobbing. Int. J. Mach. Mach. Mater. 2011, 9, 35-46. [CrossRef]

17. Klocke, F.; Brumm, M.; Staudt, J. Quality and surface of gears manufactured by free form milling with standard tools. In Proceedings of the International Gear Conference, Lyon, France, 26-28 August 2014; pp. 506-515. [CrossRef]

18. Dudás, I.; Bodzás, S.; Dudás, I.S.; Mándy, Z. Development of spiroid worm gear drive having arched profile in axial section and a new technology of spiroid worm manufacturing with lathe center displacement. Int. J. Adv. Manuf. Technol. 2015, 79, 1881-1892. [CrossRef]

19. Lin, C.; Fan, Y.; Zhang, Z. Additive manufacturing with secondary processing of curve-face gears. Int. J. Adv. Manuf. Technol. 2016, 86, 9-20. [CrossRef]

20. Li, Z.; Wang, B.; Ma, W. Comparison of ironing finishing and compressing finishing as post-forging for net-shape manufacturing. Int. J. Adv. Manuf. Technol. 2016, 86, 3333-3343. [CrossRef]

21. Hyatt, G.; Piber, M.; Chaphalkar, N.; Kleinhenz, O.; Mori, M. A Review of new strategies for gear production. Procedia CIRP 2014, 14, 72-76. [CrossRef]

22. Bouquet, J.; Hensgen, L.; Klink, A.; Jacobs, T.; Klocke, F.; Lauwers, B. Fast production of gear Prototypes-A comparison of technologies. Procedia CIRP 2014, 14, 77-82. [CrossRef] 
23. Bae, I.; Schirru, V. An approach to find optimal topological modification to duplicate tooth flank form of the existing Gear. In Proceedings of the International Gear Conference, Lyon, France, 26-28 August 2014; pp. 34-43.

24. 3-D Mathematical Modeling of Geared Mechanical Systems. Available online: http://www.spiralbevel.com/ (accessed on 1 May 2018).

25. Fuentes, A.; Ruiz-Orzaez, R.; Gonzalez-Perez, I. Computerized design, simulation of meshing, and finite element analysis of two types of geometry of curvilinear cylindrical gears. Comput. Methods Appl. Mech. Eng. 2014, 272, 321-339. [CrossRef]

26. Tang, J.; Yang, X. Research on manufacturing method of planning for spur face-gear with 4-axis CNC planer. Int. J. Adv. Manuf. Technol. 2016, 82, 847-858. [CrossRef]

27. Calleja, A.; Alonso, M.A.; Fernández, A.; Tabernero, I.; Ayesta, I.; Lamikiz, A.; López de Lacalle, L.N. Flank milling model for tool path programming of turbine blisks and compressors. Int. J. Prod. Res. 2014, 53, 3354-3369. [CrossRef]

28. López de Lacalle, L.N.; Lamikiz, A.; Sánchez, J.A.; de Bustos, I.F. Recording of real cutting forces along the milling of complex parts. Mechatronics 2006, 16, 21-32. [CrossRef]

29. Malkin, S.; Guo, C. Thermal Analysis of grinding. Ann. CIRP 2007, 56, 760-782. [CrossRef]

30. Kundrák, J.; Markopoulos, A.P.; Zarkalos, N.E. Numerical simulation of grinding with realistic representation of grinding wheel and workpiece Movements: A finite volumes study. Procedia CIRP 2017, 58, 275-280. [CrossRef]

31. Ortega, N.; Alonso, U.; Sánchez, J.A.; Pombo, I.; Plaza, S.; Izquierdo, B. Modelling of the hardening and finishing stages of grind-hardened workpieces. Int. J. Adv. Manuf. Technol. 2016, 82, 435-449. [CrossRef]

(C) 2018 by the authors. Licensee MDPI, Basel, Switzerland. This article is an open access article distributed under the terms and conditions of the Creative Commons Attribution (CC BY) license (http:/ / creativecommons.org/licenses/by/4.0/). 